\title{
Mekanize Bir Yeraltı Maden İşletmesinde Gürültü Seviyelerinin İncelenmesi
}

\author{
İlknur EROL ${ }^{* 1}$, Okan $\mathrm{SU}^{2}$ \\ ${ }^{1}$ Bülent Ecevit Üniversitesi, Mühendislik Fakültesi, Jeoloji Mühendisliği Bölümü, Zonguldak \\ ${ }^{2}$ Bülent Ecevit Üniversitesi, ZMYO, Madencilik ve Maden Çıkarma Bölümü, Zonguldak
}

Geliş tarihi:04.11.2015

Kabul tarihi:25.12.2015

\section{Özet}

Yeraltı madenciliğinde çeşitli makinelerden kaynaklanan gürültülere uzun zaman maruz kalınması çalışanlarda işitme kaybına bağlı meslek hastalıklarının oluşmasına sebebiyet vermektedir. Bu çalışmada mekanize bir yeraltı maden işletmesinde çalışan bazı maden makinalarının gürülttü seviyeleri ölçülmüştür. Daha sonra makinelerin en düşük, en yüksek, ortalama ve eşdeğer gürültü seviyeleri belirlenmiş ve işçilerin maruz kalabileceği gürülttü seviyeleri $\left(\mathrm{L}_{\mathrm{EX}, 8 \mathrm{~h}}\right)$ hesaplanmıștır. Elde edilen ölçüm sonuçları gürültü yönetmeliğine göre değerlendirildiğinde; martoperfaratörün gürültü seviyesi maruziyet sınır değerinin üzerinde (87 dBA) olduğu, kesici yükleyicinin en yüksek maruziyet eylem değerinin ( $85 \mathrm{dBA})$ üzerinde olduğu, diğer kazı ve taşıma araçlarının ise en düşük ve en yüksek maruziyet eylem değerleri (80-85 $\mathrm{dBA})$ arasında veya en düşük maruziyet eylem değerinin $(80 \mathrm{dBA})$ altında olduğu tespit edilmiştir. Sonuç olarak, mekanize bir yeraltı maden işletmesinde çalışan kazı ve taşıma araçlarının gürültü düzeylerinin iş sağlığı açısından çok yüksek olmadığı ortaya çıkmışıı.

Anahtar kelimeler: Gürülttü seviyesi, Mekanizasyon, Meslek hastalığı, İşitme kaybı

\section{Investigation of Noise Levels in a Mechanized Underground Mine}

\begin{abstract}
Long time exposure to noise, which arise from various types of mining machines, causes occupational diseases associated with hearing loss on the workers in underground mining. In this study, the noise level of some mining machines in a mechanized underground mine was measured. Then, minimum, maximum, average, and equivalent noise levels of machines were determined and also exposure of workers to noise levels $\left(\mathrm{L}_{\mathrm{EX}, 8 \mathrm{n}}\right)$ was calculated. When the results of noise measurements were evaluated according to noise regulations; it was found that $\mathrm{L}_{\mathrm{EX}, 8 \mathrm{~s}}$ of jackhammer is higher than exposure limit value $(87 \mathrm{dBA}), \mathrm{L}_{\mathrm{EX}}, 8 \mathrm{~h}$ of shearer is higher than the highest exposure value $(85 \mathrm{dBA}), \mathrm{L}_{\mathrm{EX}}, 8 \mathrm{~h}$ of other excavation and transportation machines are between the highest and lowest exposure limit value (80-85 dBA) or under the lowest exposure limit value. As a result, it is a fact that noise levels of excavation and transportation machines operated in a mechanized underground mine are not too high in terms of occupational health.
\end{abstract}

Keywords: Noise level, Mechanization, Occupational disease, Hearing loss

"Yazışmaların yapılacağı yazar: İlknur EROL, BEÜ Mühendislik Fakültesi, Jeoloji Mühendisliği Bölümü, Zonguldak,ilknurerol@beun.edu.tr 


\section{GíRIŞ}

Madencilik işleri oldukça zor şartlar altında yürütülmekte ve koşullara göre çeşitli makinalarla kazı, nakliyat ve tahkimat yapılmaktadır. Bu makinalar farklı gürültü seviyelerine sahip olmakla birlikte, uzun süre bu gürültüye maruz kalındığında geçici veya kalıcı işitme kayıplarına sebep olabilmektedir. $\mathrm{Bu}$ nedenle gürültü seviyelerinin, çalışanların sağlığının korunabilmesi ve aynı zamanda iş güvenliğinin sağlanabilmesi için limit değerlerin altında tutulması gerekmektedir.

Klasik kazı yöntemlerinden mekanize kazıya doğru geçildikçe yeraltında makinalardan daha fazla oranda yararlanılmaktadır. Böylelikle gürültü kaynaklarının sayısı ve dolayısı ile ortamdaki gürültü düzeyi de artmaktadır. Özellikle mekanize maden işletmelerinde bu durum önemli bir çevresel sorun teşkil etmekte, işçileri psikolojik olarak etkilemekte ve fiziksel performanslarını da düşürmektedir. Sonuç olarak gürültü zamanla maden işletmelerinde önemli bir meslek hastalığına sebebiyet vermektedir. $\mathrm{Bu}$ nedenle çeşitli araştırmacılar yeraltı ve yerüstünde kullanılan bazı makinalar ile laboratuvarda kurulan bazı deney düzeneklerinin gürültü ölçümleri ile ilgili çalışmalar yapmıştır. Bu bağlamda Sorin ve arkadaşları [1] yeraltında bulunan bazı gürültü kaynaklarının insan sağlığına olan etkisini değerlendirmiştir. Yeryüzü ve yeraltında çalışan darbeli delicilerin gürültü düzeyleri arasında karşılaştırma yapmışlar ve her ikisi arasında 6-8 dB'lik fark olduğunu belirlemişlerdir. Çınar ve Şensöğüt [2] linyit, feldspat ve taş ocaklarının bulunduğu açık işletmeler ve taş ocağında gürültü ölçümleri yürütmüştür. Roy ve Adhakari [3] açık işletme kömür madeninde çalışan dizel ve elektrikli maden makinalarının gürültü düzeyleri arasında karşılaştırma yapmış ve dizel makinaların daha fazla gürültü oluşturduğunu belirlemişlerdir. Kumar ve arkadaşları [4] laboratuvarda döner delik delme deney aletinde bazı delme parametrelerini değiştirerek oluşan gürültünün kayacın mekanik özellikleri üzerindeki ilişkisini çoklu regresyon analiz yöntemiyle ortaya koymuştur. Delibalta ve arkadaşları [5] elmas testere ile yaptığ çıkan gürültüden $150 \mathrm{MPa}$ dayanıma kadar olan kayaçlarda fiziko-mekanik özelliklerin güvenilebilir bir şekilde tahmin edilebildiğini ortaya koymuştur.

$\mathrm{Bu}$ çalışmada ise tam mekanize bir kömür işletmesinde ayaklarda ve galerilerde kullanılan bazı makinalara ait gürültü düzeyleri bilgisayar destekli bir gürültü ölçer ile kayıt edilmiştir. Daha sonra bütün veriler derlenmiş ve tüm makinaların eşdeğer gürültü düzeyleri hesaplanmıştır. Ayrıca, makineleri kullanan operatörlerin ve diğer işçilerin gürültü maruziyet seviyeleri $\left(\mathrm{L}_{\mathrm{EX}, 8 \mathrm{~h}}\right)$ tespit edilmiş ve elde edilen sonuçlar gürültü yönetmeliğine göre değerlendirilmiştir.

\section{GÜRÜLTÜNÜN INNSAN SAĞLIĞI ÜZERINDEKİ ETKILERI}

Gürültü, insanların işitme sağlığını ve algılamasını olumsuz etkileyen, fizyolojik ve psikolojik dengelerini bozabilen, iş performansını azaltan bir çevre kirliliği türüdür [6-7]. Gürültünün işitme duyusuna olan zararlı etkisi; insan kulağı tarafindan alınan sesin frekansına, gürültünün ses basınç seviyesine ve maruziyet süresine bağlıdır. İnsanlar üzerinde sebep olduğu sağlık sorunlarının başında işitme kaybı gelmektedir. Bu hastalık ilk bakışta gürültüye bağlı ortaya çıkan bir meslek hastalığı gibi görünse de, insan bedeni üzerindeki etkileri düşünüldüğünde iş kazalarının nedenleri içerisinde önemli bir yer oluşturmaktadır [8].

Bir kişi üzerinde gürültünün zararlı etkisinin değerlendirmesinde A ağırlıklı ses maruziyet değerleri göz önüne alınır. İşitme hasarı günlük 85 dBA veya daha fazla gürültü düzeyine maruz kalındığında oluşabilir. 85-89 dBA günlük gürültü düzeyleri yalnızca uzun süreli maruziyetlerden sonra oluşabilirken, $90 \mathrm{dBA}$ ve üzerindeki düzeylerde ise hasar riski daha yüksektir. Günlük 85 dBA'den daha az gürültü maruziyet düzeylerinin gürültü-ilişsili işitme hasarı yaratması pek olanaklı değildir. Ayrıca, sağlıklı kulakları olan kişilerde, 90 dBA'de günlük gürültü maruziyet düzeyi süresi 6 yıl, 87 dBA'da 10 yıl ve 85 dBA'de 15 yılı aşmazsa genellikle gürültü- 
ilişkili işitme hasarının oluşmayacağı varsayılabilir [9-10].

Çalışanların beden ve ruh sağlığını tehdit eden gürültünün, insan sağlığı üzerinde olumsuz etkileri dört grupta incelenebilir. Bunlar fiziksel etkiler, fizyolojik, psikolojik ve performans etkileri olarak siralanabilir.

a) Fiziksel Etkiler: Gürültünün insan sağlı̆̆1 üzerindeki en önemli fiziksel etkisi işitme duyusunda meydana getirdiği olumsuzluklardır. İşitme bozukluğu, duyma eşiğindeki yükselme olarak tanımlanmaktadır. Gürültüden kaynaklanan işitme kaybı, dünya genelinde geri dönüşü olmayan meslek hastalıklarından biri olarak kabul edilmektedir [11-12].

Gürültünün işitme duyusunda oluşturduğu olumsuz etkiler, ya ani etkiler şeklindedir ya da zamanla görülür. Ani ve yüksek bir sesin kulak zarını parçalaması ya da hassas korti organının fizyolojik yapısını düzelmeyecek şekilde bozması ani oluşan etkilerdir. Bununla birlikte ani zarar oluşturmayacak düzeydeki gürültüde uzun süre kalan kişilerde sürekli işitme kayıpları görülebilir. Yüksek ses; tüy hücrelerini zedeleyerek, korti organında çökme oluşturarak ya da işitme sinir hücrelerini etkileyerek işitme duyusuna zarar verir.

b) Fizyolojik Etkiler: Gürültü birçok hastalığında hazırlayıcısıdır. Sindirim sistemi bozuklukları, çeşitli damar hastalıkları ve şeker hastalığı gibi hastalıkların oluşması yanında hormon dengesizliklerine de neden olmaktadır. Gürültü ile birlikte incelenen titreşimin de kemik hastalıkları ve kemiklerde duruş bozukluklarına neden olduğu bilinmektedir [13].

Gerek insan gerekse hayvanlar üzerinde yapılan deneyler; gürültünün, yüksek kan basıncına (hipertansiyon), adrenalin yükselmesine, solunum hizlanmasina, adale gerilmesine ve irkilmelere neden olabileceğini ortaya koymuştur [14].

c) Psikolojik Etkiler: Gürültüye maruz kalmış kişilerde görülen en belirgin rahatsızlık belirtisi karşılığı "annoyance" olarak tanımlanan sıkıntı ve gerilim duygusudur. Gürültü yeteri kadar yüksek ve kaynağ yeteri kadar fazla ise rahatsızlık daha fazla olacağından, aşırı duygusal tepkiler ve davranış bozuklukları gözlenecektir [15].

d) Performans Etkileri: Performans etkileri; iş veriminin düşmesi, konsantrasyon bozukluğu, hareketlerin engellenmesidir. Gürültü nedeniyle belli bir frekans aralığında oluşan kalıcı işitme kaybı diğer frekanslardaki seslerin duyulmasını ve algılanmasını etkilemez, ancak bazı fonksiyonların bozulmasina neden olabilir [16].

\section{MEKANIZE BİR ISLETMEDE GÜRÜLTÜ ÖLÇÜMLERİ}

Madencilikte iş sağlığı ve güvenliği prensipleri çerçevesinde kısa zamanda en yüksek üretim ve maksimum kar elde etmek en temel hedeflerdendir. Bu hedefe ulaşabilmek, madencilik işlerinin galeri açma makinaları ve kesici yükleyici gibi mekanize kazı araçlarıyla yapılmasıyla mümkün olabilir. Bunun yanı sıra gerek personel taşıma gerekse de cevher ve çeşitli makine parçalarını taşımada kullanılan monoray sistemleri, telesiyej sistemi, zincirli oluklar, vb. makinalar bu ocakların vazgeçilmez elemanlarıdır.

Mekanizasyonun uygulanabilmesi temelde damarın karakteristik özelliklerine ve yeraltındaki koşullara bağlı olmakla birlikte sermaye de önemli bir etkendir. Çünkü cevherin yeraltındaki konumuna göre seçilecek makine ve ekipmanları satın almak büyük yatırımlar gerektirmektedir. Klasik kazıda kullanılan ekipmanlar ise daha ucuz ve basit sistemlerdir.

Mekanize kazıda işletmedeki toplam işçi sayıları azalsa da, kullanılan makine sayısı arttığı için iş sağlığı ve güvenliği önlemlerinin arttırılması gerekmektedir. $\mathrm{Bu}$ amaçla göz önüne alınması gereken etmenlerden birisi makinaların oluşturduğu gürültüdür.

$\mathrm{Bu}$ çalışmada tam mekanize bir yeraltı maden işletmesinin iki farklı ocağına desandrelerden inilmiştir. Hazırlık galerilerinin sürüldüğü ve kömür kazısının yapıldığı ayaklardak gürültü 
kaynakları incelenmiştir (Çizelge 1).

Çizelge 1. Gürültü ölçümü yapılan makineler

\begin{tabular}{|l|l|}
\hline Makine Türü & Görevi \\
\hline Kesici yükleyici & Kömür kazısı \\
\hline Galeri açma makinas1 & Galeri sürme \\
\hline Martoperfaratör & Delik delme \\
\hline Zincirli oluk & Kömür taşıma \\
\hline Bant & Pasa taşma \\
\hline $\begin{array}{l}\text { Dizel lokomotif } \\
\text { (Monoray sistem) }\end{array}$ & $\begin{array}{l}\text { Personel ve makine } \\
\text { parçaları nakliyesi }\end{array}$ \\
\hline Çeneli kırıcı & Boyut küçültme \\
\hline
\end{tabular}

Sahadaki gürültü ölçümlerinde PCE-322A marka gürültü ölçer kullanılmıştır. Cihazın teknik özellikleri Çizelge 2'de verilmiş̧ir.

Çizelge 2. PCE-322A gürültü ölçerin özellikleri

\begin{tabular}{|l|l|}
\hline Ölçüm Alanı & $30 \ldots 130 \mathrm{~dB}$ \\
\hline Çözünürlük & $0,1 \mathrm{~dB}$ \\
\hline Hassasiyet & $\pm 1,4 \mathrm{~dB}$ \\
\hline Frekans & $31,5 \mathrm{~Hz} \ldots 8000 \mathrm{~Hz}$ \\
\hline Veri toplayıcı & 262.100 nokta \\
\hline Değerlendirme & $\mathrm{A}, \mathrm{C}$ \\
\hline Örnekleme & Hızlı, Yavaş \\
\hline
\end{tabular}

Gürültü ölçümleri, A ağırlıklı ses düzeyinde ve yavaş modda yapılmıştır. Elde edilen veriler daha sonra Eşitlik 1'den yararlanılarak eşdeğer:

$L_{\text {Aeq }}=10 \cdot \log \left[\left(\frac{1}{n}\right) \sum_{i=1}^{n} 10^{L_{i} / 10}\right]$

$\mathrm{L}_{\text {Aeq }}$ : Eşdeğer gürültü seviyesi (dBA)

$\mathrm{n}:$ Ölçüm sayısı

$\mathrm{L}_{\mathrm{i}}$ : Ölçüm değerleri (dBA)

Yeraltında yapılan ölçüm sonuçlarına göre makinaların eşdeğer gürültü seviyesi belirlendikten sonra, makineleri kullanan operatörlerin ve civarında çalışan işçilerin çalışma süreleri esas alınarak günlük kişisel gürültü etkilenme düzeyi $\left(\mathrm{L}_{\mathrm{EX}}\right.$, sh $)$ hesaplanmıştır. Bu bağlamda 8 saatlik çalışma süresince maruz kalınan gürültü seviyesi Eşitlik 2'den belirlenir [17].

$L_{E X, 8 h}=L_{A e q}+10 \log \left[\frac{T_{e}}{T_{0}}\right]$

$\mathrm{L}_{\text {Aeq }}$ : Eşdeğer gürültü düzeyi (dBA).

$T_{e}$ : Çalışma gününde etkin olarak maruz kalınan periyot (saat).

$\mathrm{T}_{0}$ : Referans maruz kalma periyodu (= 8 saat).

\subsection{Kazı Makinalarının Gürülttü Düzeyleri}

Madencilik faaliyetlerinin tam mekanize yürütüldüğü yeraltı kömür işletmelerinde galeriler genellikle galeri açma makinaları ile sürülürken, üretim kesici yükleyiciler ile yapılmaktadır. Bu çalışmada tam mekanize çalışan bir yeraltı işletmesinde her iki makinanın gürültü düzeyleri ölçülmüştür.

\subsubsection{Kesici Yükleyici Gürültü Düzeyi}

Kesici yükleyiciler mekanize ayaklarda kullanılan vazgeçilmez makinalardır (Şekil 1). $\mathrm{Bu}$ makinalarda temel olarak tek veya çift tambur ve bu tamburlarla birlikte ayak içinde çalışan zincirli oluklar bulunmaktadır.

Arazi çalışmaları sırasında ilk olarak kesici yükleyici tamburları boşta iken ve daha sonra üretim sırasındaki gürültü düzeyleri ölçülmüsstür (Şekil 2). Ayrıca zincirli oluğun (Z.O.) kazı sırasında çıkardığı gürültünün etkisi incelenmiştir. Ölçüm sonuçlarında minimum $\left(\mathrm{L}_{\text {min }}\right)$, maksimum $\left(\mathrm{L}_{\max }\right)$ ve ortalama gürültü düzeyleri $\left(\mathrm{L}_{\text {ort }}\right)$ ile Eşitlik 1'den eşdeğer gürültü seviyesi $\left(\mathrm{L}_{\mathrm{Aeq}}\right)$ hesaplanmıştır, Makinaların eşdeğer gürültü düzeyi tespit edildikten sonra, işçilerin maruz kaldığ 1 gürültü düzeyi $\left(\mathrm{L}_{\mathrm{EX}, 8 \mathrm{~h}}\right)$ hesaplanmıştır. (Çizelge 3). Çizelge 3 'ten görüleceği üzere kesici yükleyicinin tamburları boşta iken (henüz kazı yapılmıyor) eşdeğer gürültü düzeyi 77,4 dBA'dır. Zincirli oluk ünitesi çalıştırılmadan tamburlar kömür içerisinde kazıya başladığında (su fisketeleri çalışıyor iken) eşdeğer gürültü düzeyi 85,8 dBA'ya çıkmaktadır. 


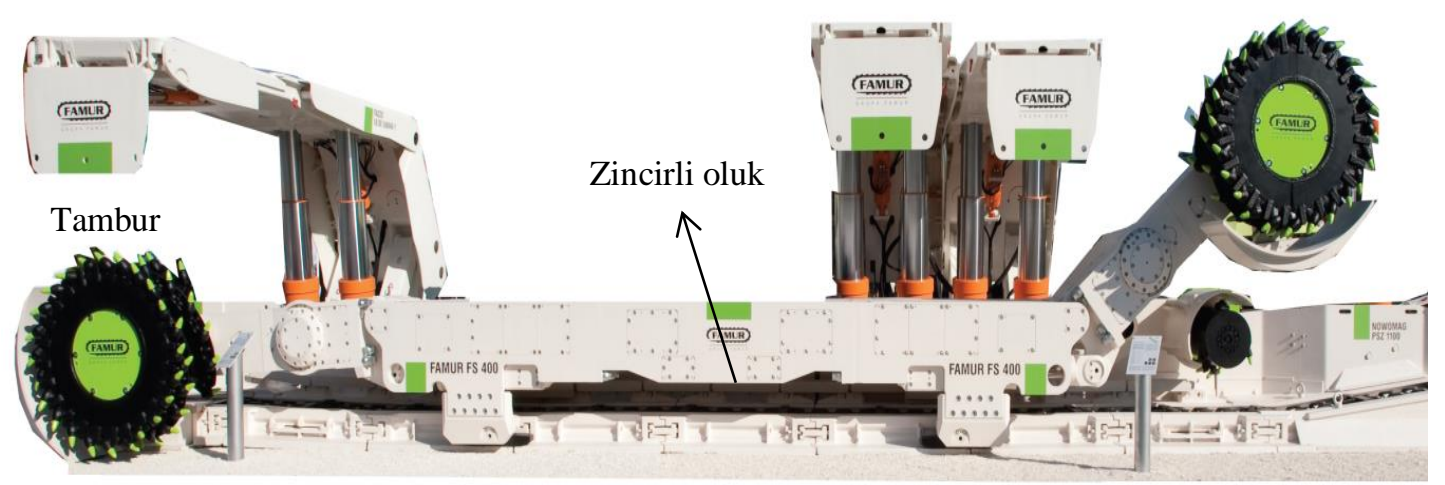

Şekil 1. Kesici-yükleyici bir makinanın genel görünümü [18]

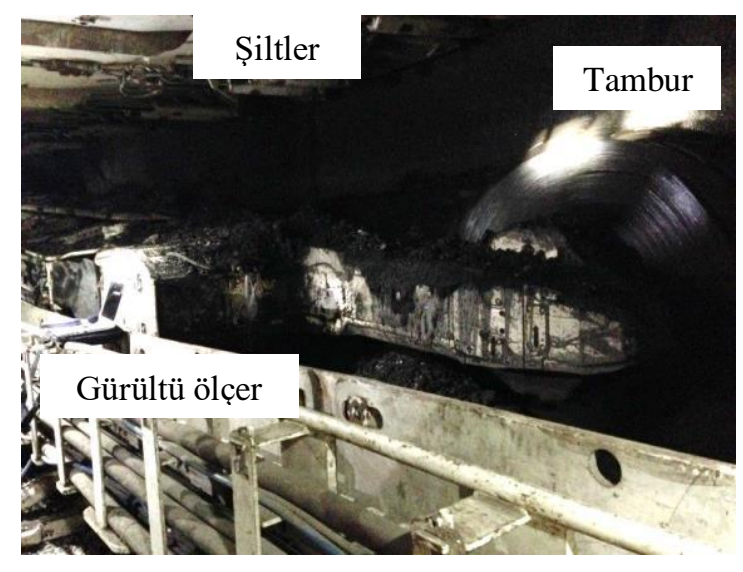

Şekil 2. Ayak içerisinde gürültü ölçerin konumlandirılması

Çizelge 3. Kesici yükleyicinin gürültü ölçüm sonuçları (dBA)

\begin{tabular}{|c|c|c|c|c|c|}
\hline $\begin{array}{c}\text { Tambur } \\
\text { konumu }\end{array}$ & $\mathbf{L}_{\min }$ & $\mathbf{L}_{\mathbf{m a x}}$ & $\mathbf{L}_{\text {ort }}$ & $\mathbf{L}_{\text {Aeq }}$ & $\mathbf{L}_{\mathbf{E X , 8 h}}$ \\
\hline Tmb. boşta & 73,4 & 84,3 & 76,6 & 77,4 & 74,4 \\
\hline Tmb. yükte & 77,0 & 92,4 & 84,3 & 85,8 & 82,8 \\
\hline $\begin{array}{c}\text { Tmb. yükte } \\
+ \text { Zin. Oluk }\end{array}$ & 80,9 & 89,8 & 84,8 & 85,2 & 82,1 \\
\hline $\begin{array}{c}\text { Tmb. yükte } \\
\text { (hizl1)+ Z.O. }\end{array}$ & 78,4 & 92,4 & 87,3 & 88,4 & 85,4 \\
\hline
\end{tabular}

Kazı sırasında zincirli oluk çalıştırıldığında gürültü düzeyinde çok büyük bir değişiklik gözlenmeksizin yine $85 \mathrm{dBA}$ civarında olduğu belirlenmiştir. Ancak, kesici yükleyicinin ayak içerisindeki hızı arttırıldığında gürültü düzeyinin 88,4 dBA'ya çıktığı görülmüştür. Dolayısı ile bu koşullara göre gürültü kazı hızı arttırıldığında kesici tamburların zincirli oluktan daha fazla gürültü çıkardığg görülmüştür.

Kesici yükleyicilerde makinadan faydalanma oranı (MFO) \%40-60 arasında değişmektedir [19]. Buna göre MFO \%50 kabul edildiğinde 8 saatlik bir vardiyada kesicinin 4 saat çalıştığı esas alınmıştır. Ancak ayağın, panonun ve diğer çevre koşullarının durumuna göre bu süre zaman zaman artabilir veya azalabilir. Bu bağlamda operatör ve diğer işçilerin 85,4 dBA civarında gürültüye maruz kaldığı tespit edilmiştir. Diğer taraftan, kesici yükleyici üzerindeki yürüyen tahkimat üniteleri kazının durumuna göre kesintili çalışmaktadır. Bu nedenle bu ünitelerin gürültüleri ölçülmemiştir.

Kesici yükleyicinin kazdığı parçalar iri boyutlarda olabilmektedir. Dolayısıyla ayak dibinde, kazılan tüvenan kömürün boyutunu küçültmek üzere kurulmuş olan bir çeneli kırıcı bulunmaktadır. Kömür zincirli oluktan bu kırıcıya beslenmektedir. $\mathrm{Bu}$ bağlamda ayak dibinde kırıcının ve zincirli oluğun birlikte çıkardığı gürültü mevcuttur (Çizelge 4). 
Çizelge 4. Kırıcı gürültü düzeyleri (dBA)

\begin{tabular}{|c|c|c|c|c|c|}
\hline Kırıcı & $\mathbf{L}_{\text {min }}$ & $\mathbf{L}_{\text {max }}$ & $\mathbf{L}_{\text {ort }}$ & $\mathbf{L}_{\text {Aeq }}$ & $\mathbf{L}_{\mathbf{E X , 8 h}}$ \\
\hline Kırıcı boşta & 75,2 & 85,4 & 80,4 & 81,2 & 78,1 \\
\hline $\begin{array}{c}\text { Kırıcı yükte } \\
\text { + Zin.Oluk }\end{array}$ & 78,8 & 89,8 & 85,0 & 85,2 & 82,2 \\
\hline
\end{tabular}

Çizelge 4'ten görüleceği üzere; kırıcının boşta çıkardığı ortalama gürülttü düzeyi $80,4 \mathrm{dBA}$ ve eşdeğer gürültü düzeyi 81,2 dBA'dır. Kırıcıya kömür beslemeye başladıktan sonra ortalama gürültü düzeyi 85 dBA'ya ve eşdeğer gürültü düzeyi de 85,2 dBA'ya çıkmaktadır. Ayrıca, kırıcının etrafında bulunan iş̧̧iler 4 saat sonunda 82,2 dBA gürültüye maruz kalmaktadırlar.

\subsubsection{Galeri Açma Makinası Gürültü Düzeyi}

Tam mekanize maden işletmesinde koşullara bağlı olarak genellikle galeriler galeri açma makinaları (GAM) ile sürülmektedir. Bu çalışmada kol ekseni dönme eksenine paralel tip GAM ile trapez şekilli B24 kesitte kömür ve killi kayaç içerisinde sürülen galeri arınında gürültü ölçümleri yapılmıştır. Kazı yapilan formasyonda ara kesmeler de bulunmaktadır. Dolayısı ile ara kesmelerin gürültü düzeyine olan etkisi de göz önüne alınmıştır.
Kazı sırasında arına girmek tehlikeli olduğu için kesici kafanın yakınında ölçüm yapılmamıştır. Bu nedenle ilk ölçüm GAM operatörünün olduğu noktadan (arına $5 \mathrm{~m}$ uzaklıkta) ve 10 ve $15 \mathrm{~m}$ mesafelerden yürütülmüştür. Ayrıca, $6 \mathrm{~m}$ taban genişliği olan galeride arını ortasından, sol tarafindan ve sağ tarafindan ölçümler alınmıştır. Daha sonra tüm ölçüm verilerinin aritmetik ortalamaları ve yine Eşitlik 1'den eşdeğer gürültü düzeyleri hesaplanmıştır. Bunun yanı sıra, galeri açma makinalarında makinadan faydalanma oranı (MFO) \%25-40 arasında değişmektedir [19]. Bu bağlamda MFO \%38 olan bir makine için 8 saatlik bir vardiyada makinanın 3 saat çalıştığı göz önüne alınarak yapılan hesaplama sonucuna göre işçilerin maruz kaldığ1 gürültü düzeyi $\left(\mathrm{L}_{\mathrm{EX}, 8 \mathrm{~h}}\right)$ değerleri sunulmuştur (Çizelge 5).

Çizelge 5'teki sonuçlara göre GAM'dan kazı sırasında ölçülen eşdeğer gürültü seviyeleri $5 \mathrm{~m}$ mesafede $88 \mathrm{dBA}, 10 \mathrm{~m}$ mesafede $84 \mathrm{dBA}$ ve 15 $\mathrm{m}$ mesafede de $82 \mathrm{dBA}$ olarak belirlenmiştir. Ancak kesici kafa ara kesme içerisine girdiğinde gürültü seviyesi 90 dBA'ya kadar çıkmaktadır. Ölçüm sonuçlarına göre galeri arınının plan kesiti çizilmiş ve hesaplanan eşdeğer gürültü seviyeleri bu kesit üzerinde gösterilmiştir (Şekil 3). Diğer taraftan GAM operatörü ve diğer işçilerin 3 saatte maruz kaldığ 1 gürültü düzeyinin $82-86 \mathrm{dBA}$ arasında olduğu belirlenmiştir.

Çizelge 5. Galeri açma makinasının farklı uzaklıklarda ve konumlarda gürültü ölçüm sonuçları (dBA)

\begin{tabular}{|c|c|c|c|c|c|c|}
\hline \multicolumn{2}{|c|}{ Arına olan ölçüm mesafesi } & \multirow{2}{*}{$\begin{array}{l}\mathbf{L}_{\text {min }} \\
78,9\end{array}$} & \multirow{2}{*}{$\begin{array}{l}\mathbf{L}_{\text {max }} \\
92,1\end{array}$} & \multirow{2}{*}{$\begin{array}{l}\mathbf{L}_{\text {ort }} \\
85,1\end{array}$} & \multirow{2}{*}{$\begin{array}{l}\mathbf{L}_{\text {Aeq }} \\
86,3\end{array}$} & \multirow{2}{*}{$\begin{array}{r}\mathbf{L}_{\mathrm{EX}, 8 \mathrm{~h}} \\
82,0\end{array}$} \\
\hline \multirow{4}{*}{$\begin{array}{l}\Xi \\
\text { n }\end{array}$} & 1.ölçüm-ortada & & & & & \\
\hline & 2.ölçüm-sol taraf & 80,5 & 92,5 & 86,6 & 87,6 & 83,3 \\
\hline & 3.ölçüm-sağ taraf & 77,5 & 93,9 & 86,9 & 88,1 & 83,8 \\
\hline & Ara kesme-ortada & 78,5 & 97,1 & 88,0 & 90,0 & 85,7 \\
\hline \multirow{3}{*}{$\stackrel{\Xi}{\varrho}$} & 1.ölçüm-ortada & 79,4 & 89,0 & 83,3 & 84,0 & 79,7 \\
\hline & 2.ölçüm-sol taraf & 80,6 & 89,2 & 83,8 & 84,2 & 79,9 \\
\hline & 3.ölçüm-sağ taraf & 79,6 & 87,7 & 82,7 & 83,7 & 79,4 \\
\hline \multirow{3}{*}{$\begin{array}{l}\Xi \\
\curvearrowleft\end{array}$} & 1.ölçüm-ortada & 78,1 & 86,5 & 80,6 & 81,4 & 77,1 \\
\hline & 2.ölçüm-sol taraf & 78,2 & 86,2 & 80,9 & 81,4 & 77,1 \\
\hline & 3.ölçüm-sağ taraf & 78,4 & 86,7 & 80,8 & 81,6 & 77,3 \\
\hline
\end{tabular}




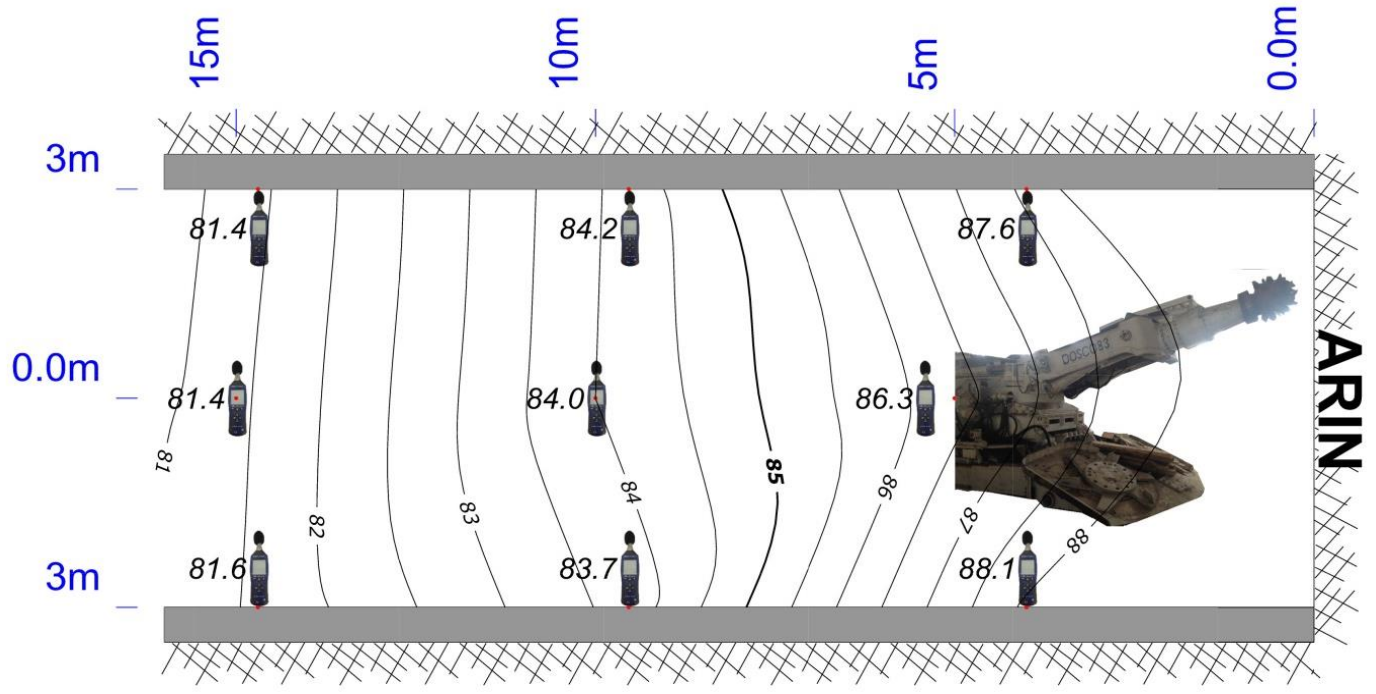

Şekil 3. Galeri açma makinasının arın içerisindeki eşdeğer gürültü düzeyi haritası

GAM kazdığı pasayı arka tarafindaki bant konveyöre aktarmaktadır. Kazı ilerledikçe konveyör ötelenmektedir. Bu amaçla konveyörün ayaklarını sabitlemek üzere martoperfaratör kullanılarak tabana cıvata delikleri açılmaktadır. Kazı işlerinin duraksamasına sebep olan bu süreçte martoperfaratörün gürültü düzeyi de makinanın yanında ölçülmüştür. Buna göre $\mathrm{L}_{\min } 93,6 \mathrm{dBA}$, $\mathrm{L}_{\max } 105,9 \mathrm{dBA}, \mathrm{L}_{\text {ort }}$ 99,6 dBA olduğu görülmüş ve ayrıca $\mathrm{L}_{\mathrm{Aeq}}$ 99,9 dBA olarak hesaplanmıştır. Yapılan bu işlerin yarım saat sürdüğü dikkate alındığında burada çalışan işçilerin maruz kaldığı gürültü düzeyi 87,9 dBA olarak hesaplanmıştır.

Bu sonuçlar 1şığında, işçilerin kazı sırasında maruz kaldıkları gürültü düzeyinin, bandın uzatılması sırasındaki gürültü düzeyinden düşük olduğu tespit edilmiştir.

\subsection{Taşıma Araçlarının Gürültü Seviyeleri}

Mekanize bir maden işletmesinde taşıma araçları üretimin sürekliliğini etkilemektedirler. Yeryüzündeki hareket noktası veya stok sahasından yeraltındaki üretim noktasına kadar aralıksız olarak çalışırlar. $\mathrm{Bu}$ nedenle mekanize maden işletmesinde çalışan kazı makinalarının yanı sıra lokomotif, zincirli oluk ve bantlı konveyör, gibi taşıma araçlarının da gürültü düzeyleri önemlidir.

$\mathrm{Bu}$ çalışmada tavana asılı ray üzerinde hareket eden monoray sisteminde çalışan bir dizel lokomotifin operatör kabinine yansıya gürültü düzeyi esas alınmıştır. Desandre boyunca personel taşıma ve ağır makine parçalarının çekilmesinde kullanılan bu lokomotifin minimum, maksimum ve ortalama gürültü düzeyleri Çizelge 6'da sunulmuştur. Ayrica lokomotifin 1 sefer seyahat süresi yarım saat kabul edildiğinde hesaplanan $\mathrm{L}_{\mathrm{EX}, 8 \mathrm{~h}}$ değeri yine aynı çizelgede verilmiştir.

Diğer taraftan zincirli oluk ayak içinde kesici yükleyiciyle birlikte, bantlı konveyör ise galeri açma makinasının arkasında çalışmaktadır. Buna göre tüm bu taşıma araçlarının kazı makinalarıyla eşdeğer sürede (zincirli oluk 4 saat, bant konveyör 3 saat) çalıştığı göz önüne alındığında, taşıma aracının etrafinda bulunan işçilerin maruz kaldıkları gürültü düzeyleri yine Çizelge 6'da sunulmuştur.

Ölçüm sonuçlarına göre en gürültüsüz çalışan taşıma aracı 73,2 dBA ile bant konveyördür. 
Çizelge 6. Taşıma araçlarına ait gürültü ölçüm sonuçları (dBA)

\begin{tabular}{|l|l|c|c|c|c|c|}
\hline Taşıma aracı & Taşınan malzeme & $\mathrm{L}_{\min }$ & $\mathrm{L}_{\max }$ & $\mathrm{L}_{\text {ort }}$ & $\mathrm{L}_{\text {Aeq }}$ & $\mathrm{L}_{\mathrm{EX}, 8 \mathrm{~h}}$ \\
\hline Zincirli oluk (1. ölçüm) & Kömür & 81,4 & 90,3 & 84,0 & 84,5 & 81,5 \\
\hline Zincirli oluk (2. ölçüm) & Kömür & 88,3 & 90,7 & 89,6 & 89,6 & 86,6 \\
\hline Bantlı konveyör & Pasa & 71,8 & 76,3 & 73,1 & 73,2 & 61,2 \\
\hline Dizel lokomotif (yavaş) & Personel & 82,0 & 89,8 & 86,1 & 86,5 & 74,5 \\
\hline Dizel lokomotif (hızlı) & Ağır makine parçası & 86,5 & 94,8 & 91,1 & 91,4 & 76,4 \\
\hline
\end{tabular}

Bunun yanı sıra zincirli oluğun ortalama gürültü seviyesi $84 \mathrm{dBA}$ (1. ölçüm) iken, tahrik motorunun yanında ise 89,6 dBA'ya (2. ölçüm) artmıştır. Diğer taraftan lokomotif personel taşırken, yani düşük hızda 86,5 dBA, makine parçası vb. malzemeleri taşırken ise 91,4 dBA'dır. Gürültüye sebep olan k1sim ise monoray sisteminde tavana bağlı olan raylarının bağlantı noktalarıdır. Lokomotif ve vagonları bu noktalardan geçerken gürültü düzeyi artmaktadır.

Çizelge 6'daki sonuçlara göre taşıma araçlarına ve maruziyet sürelerine bağlı olarak işçilerin en fazla zincirli oluğun gürültüsünden etkilenebileceği, diğer taşıma araçlarının ise çok fazla gürültülü olmadığ kanısına varılmıştır.

\section{GÜRÜLTÜ ÖLCÜMLERININ DEĞERLENDİRILMESI}

Tam mekanize bir yeraltı maden işletmesinde kullanılmakta olan makinaların gürültü düzeyleri, "Çalışanların Gürültü İle İlgili Risklerden Korunmalarına Dair Yönetmelik”e göre değerlendirilmiştir. $\mathrm{Bu}$ yönetmelikte, günlük gürültü maruziyet düzeyi $\left(\mathrm{L}_{\mathrm{EX}}, 8 \mathrm{~h}\right)$; TS2607ISO1999 standardında tanımlandığı gibi anlık darbeli gürültünün de dahil olduğu A ağırlıklı bütün maruziyet düzeylerinin, 8 saatlik bir iş günü için, zaman ağırlıklı ortalamasıdır. Bu bağlamda en düşük maruziyet eylem değerleri $80 \mathrm{dBA}$ ve 135 $\mathrm{dBC}$; en yüksek maruziyet eylem değerleri $85 \mathrm{dBA}$ ve $137 \mathrm{dBC}$; maruziyet sınır değerleri ise $87 \mathrm{dBA}$ ve $140 \mathrm{dBC}$ 'dir [20]. Yönetmelikte belirtilen bu değerler 1şı̆̆ında işletmede çalışan makina operatörleri ve işçilerin gürültüye maruz kalma süreleri esas alınarak elde edilen sonuçlar arasında mukayese yapılmıştır (Şekil 4).

Şekil 4'te verilen sonuçlara göre kazı makinelerinin (martoperfaratör, kesici yükleyici ve galeri açma makinası) taşıma araçlarına göre daha gürültülü olduğu belirlenmiştir. Ancak, bunların içerisinde sadece martoperferatör 8 saatlik bir işgünü için maruziyet sınır değeri olan $\mathrm{L}_{\mathrm{EX}, 8 \mathrm{~h}}=87 \mathrm{dBA}$ 'da aşmakta, kesici yükleyici ise en yüksek maruziyet eylem değerindedir. KY'nin kesme hızındaki değişimin gürültü düzeyinde de oldukça etkili olduğu görülmüştür. Martoperfaratörlerin civarında çalışan işçiler sadece bandın taban civataları takılıncaya kadar (yani yarım saat) gürültüye maruz kalmaktadırlar. Ancak, aynı işin sürekli tekrarlandığı göz önüne alındığında kulak koruyucu donanımları takmaları şarttır.

Galeri açma makinasına $5 \mathrm{~m}$ mesafedeki maruz kalınan gürültü seviyesi en düşük ve en yüksek maruziyet eylem değerleri arasında iken, makine ara kesmeye girdiğinde ise gürültü seviyesinin maruziyet sınır değerine yaklaştığı görülmüştür. Ayrıca makinadan uzaklaştıkça $(>10 \mathrm{~m})$ gürültü seviyesi en düşük maruziyet eylem değerinin (80 $\mathrm{dBA}$ ) altına düşmektedir.

Diğer taraftan taşıma araçlarının genel olarak çok gürültülü olmadığı belirlenmiştir. Bunların içinde zincirli oluk en düşük maruziyet eylem değerine (80 dBA) yakın iken, dizel lokomotif ve bant konveyörün etrafında çalışan işçilerin bu gürültü düzeyinden çok fazla etkilenmediği belirlenmiştir. Kazı ve taşıma araçlarının yanı sıra kesici 
yükleyiciyle aynı sürelerde çalışan ve ayak dibinde bulunan çeneli kırıcının da gürültü maruziyet düzeyinin en düşük ve en yüksek maruziyet eylem değerleri arasında olduğu tespit edilmiştir. $\mathrm{Bu}$ nedenle kırıciyı kontrol eden operatör ve etrafindaki diğer işçilerin de kulak koruyucu kullanmaları gerekmektedir.

Tüm bu ölçümlerin yanı sıra havalandırmada kullanılan fanlar ve kompresörler maden işletmelerindeki önemli gürültü kaynakları olduğu bilinmektedir. Ancak, ölçümlerin yapıldığı maden işletmesinde bu kaynaklar yeryüzünde bulunduğu için değerlendirmeye alınmamıştır.

\section{SONUÇ VE ÖNERÍLER}

Mekanizasyonun uygulandığı yeraltı maden işletmelerinde gerek kazı ve gerek taşıma amaçlı kullanılan makine sayıları fazladır. Bu nedenle bu ocaklarda karşılaşılan önemli çevresel problemlerden birisi makinaların çıkardıkları gürültü düzeyi ve buna bağlı olarak çalışan işçilerde oluşan işitme kayıplarıdır.

$\mathrm{Bu}$ çalışmada mekanize bir yeraltı maden işletmesinde çalışan kazı makineleri, taşıma araçları vb. makinelerin gürültü seviyeleri ölçülmüştür. Elde edilen sonuçlara göre kazı makinalarının gürültü düzeylerinin taşıma araçlarından daha yüksek olduğu tespit edilmiştir.

Yönetmelikte verilen gürültü sınır değerleri baz alındığında martoperfaratörün maruziyet sınır değerinin ( $>87 \mathrm{dBA}$ ) üzerinde, kesici yükleyicinin ise en yüksek maruziyet eylem değerinin (85 dBA) üzerinde olduğu belirlenmiştir. Ayrıca, galeri açma makinası, çeneli kırıcı ve zincirli oluğun en düşük ve en yüksek maruziyet eylem değerleri (80-85 dBA) arasında, lokomotif ile bant konveyörün ise en düşük maruziyet eylem değerinin altında kaldığ bu değerler makinadan faydalanma oranına göre değişiklik gösterebilir. Dolayısı ile gerek ayakta ve gerekse de galerilerde martoperfaratör dişındaki diğer makinalarda sürekli çalışan operatör ve işçilerin gürültü düzeyine uygun kulak koruyucu kullanmalarına gerek bulunmamaktadır. $\mathrm{Bu}$ bağlamda martoperfaratör ile delik delmek gürültüye bağlı işitme kaybı yönünden en riskli iş sanatından olduğu söylenebilir.

Makineleri kullanan operatörler dışında, aynı işyerinde çalışan işçilerin işitme kaybına yakalanmamaları için her makinenin etrafında gürültü etki alanı belirlenmelidir. Maden işletmelerinde tüm gürültü kaynaklarının ölçümleri yapılmalı, ölçüm sonuçlarına göre gürültü haritaları çizilmelidir. Ölçümler belirli periyotlarda tekrarlanmalı, sonuçlara göre haritalar da güncellenmelidir.

İşletme tarafindan da, kulak koruyucu donanımların çalışanlar tarafından kullanımının sağlanması ve sikı bir şekilde denetlenmesi gerekmektedir. Gerektiğinde cezai işlem de uygulanmalıdır. Ayrıca, burada çalışanların her altı ayda bir odyogramları alınmalıdır.

İyi bir iş oganizasyonu ile iş yerlerindeki gürültü düzeyine göre işçilerin çalışma süreleri ayarlanarak, uygun sürede mola verilerek işçilerin geçici veya kalıcı işitme kayıplarına yakalanmaları önlenebilir. Makinelerde ses yalıtım sistemlerinin bulundurulması ve mekanizasyon ünitelerinin periyodik bakımlarının yapılması alınabilecek diğer önlemlerdendir.

\section{TEŞEKKÜR}

Yazarlar, bu çalışmanın gerçekleştirilmesinde ve proje süresince maddi destek sağlayan BEÜ Bilimsel Araştırmalar Proje Birimi’ne (201429011448-01) ve arazi çalışmalarında her türlü desteğini esirgemeyen Maden Yük. Müh. Metin ONAN'a teşekkürü bir borç bilir.

\section{KAYNAKLAR}

1. Sorin, S., Ciprian, V., Marius, K., Lorand, T., 2013. Exposure of Workers to Noise in Mining Ind. Appl Mech Mater 430, 281-284.

2. Cinar, I., Sensogut, C., 2013. Evaluation of Noise Measurements Performed in Mining Sites for Environmental Aspects. Int J Environ Res 7, 383-386. 
3. Roy, S., Adhikari, G.R., 2007. Worker Noise Exposures from Diesel and Electric Surface Coal Mining Machinery. Noise Control Eng J 55, 434-437.

4. Kumar, B.R., Vardhan, H., Govindaraj, M., 2011. Sound Level Produced During Rock Drilling vis-a-vis Rock Properties. Eng Geol 123, 333-337.

5. Delibalta, M.S., Kahraman, S., Comakli, R., 2015. The Usability of Noise Level from Rock Cutting for the Prediction of PhysicoMechanical Properties of Rocks. Fluct Noise Lett 14 (1), 12 p.

6. Hasgür, İ., 1998. Gürültü Kirliliğinin Türk Mevzuatındaki Yeri. Çevre Dergisi, s. 31-33.

7. Kurtuluş, C., Endeş, H., 1998. İzmit'te Karayolu ve Demiryolunda Taşıt Gürültüsünü Etkileyen Etmenlerin İncelenmesi, Uygulamal1 Yerbilimleri, 1 (1), 31-38.

8. Şensöğüt, C., Çınar İ., 2006. Açık Ocaklarda Gürültü Yayılımının Geliştirilen Bir Model ile İncelenmesi, Madencilik, 45 (3), s. 27-33.

9. Berk, M., Önal, B., Güven, R., 2011. Meslek Hastalıkları Rehberi, Çalışma ve Sosyal Güvenlik Bakanlığı, İş Sağlığı ve Güvenliği Genel Müdürlüğü, 245-256, Ankara.

10. Yost, W.A., 2007. Hearing Thresholds, Loudness of Sound and Sound Adaptation in, Handbook of Noise and Vibration Control, pp. 286-292, Ed Crocker, M.J., John Wiley\&Sons, New York.

11. Mcbridge, D.I., 2004. Noise-Induced Hearing Loss and Hearing Conservation in Mining, Occupational Medicine, 54, 290-296.

12. May, J.J., 2000. Occupational Hearing Loss. Am J Ind Med 37, 112-120.

13. Çakar, Y. 1988. İşyerlerinde Gürültü, Titreşim ve Işınların İnsan Sağlığına Zararları ve Koruma, Mühendis ve Makina, 29 (336), 2 s.

14. Lusk, S.L., Hagerty, B.M., Gillespie, B., Caruso, C.C., 2002. Chronic Effects of Workplace Noise on Blood Pressure and Heart Rate. Arch Environ Health 57, 273-281.

15. Çınar, İ., 2005. Madencilikte Gürültü Analizi, Modellenmesi ve Haritalanmas1, Doktora Tezi, Fen Bilimleri Enstitüsü, Selçuk Üniversitesi, Konya, s 141.
16. Onur, A.H., 2015. Meslek Hastalıkları, Dokuz Eylül Üniversitesi, Mühendislik-Mimarlık Fakültesi, Maden Müh. Bölümü, İzmir.

17. TS2607 ISO 1999, 2005. Akustik-İş Yerinde Maruz Kalınan Gürültünün Tayini ve $\mathrm{Bu}$ Gürültünün Sebep Olduğu İşitme Kaybının Tahmini, Türk Standardı, Ankara, 26 s.

18. Famur, 2012. Famur Kesici Yükleyici Katoloğu, Katowice, Polonya, 8 s.

19. Bilgin, N., Copur, H., ve Balc1, C. 2014. Mechanical Excavation in Mining and Civil Industries. $1^{\text {st }}$ edn. CRC Press, New York.

20. Gürültü Yönetmeliği, 2013. Çalışma ve Sosyal Güvenlik Bakanlığı, Resmi Gazete, 28.07.2013 Tarih, Sayı 28721, Ankara. 